\title{
Beyond the numbers: institutional influences on experiences with diversity on elite college campuses
}

\section{Citation}

Warikoo, Natasha K., and Sherry L. Deckman. 2014. Beyond the numbers: institutional influences on experiences with diversity on elite college campuses. Sociological Forum 29, no. 4: 959-981.

\section{Published Version}

http://onlinelibrary.wiley.com/doi/10.1111/socf.12128/abstract

\section{Permanent link}

http://nrs.harvard.edu/urn-3:HUL.InstRepos:23922470

\section{Terms of Use}

This article was downloaded from Harvard University's DASH repository, and is made available under the terms and conditions applicable to Open Access Policy Articles, as set forth at http:// nrs.harvard.edu/urn-3:HUL.InstRepos:dash.current.terms-of-use\#OAP

\section{Share Your Story}

The Harvard community has made this article openly available.

Please share how this access benefits you. Submit a story.

\section{Accessibility}




\title{
Beyond the Numbers: Institutional Influences on Experiences with Diversity on Elite College Campuses ${ }^{1}$
}

Authors: Natasha K. Warikoo ${ }^{2}$ and Sherry L. Deckman ${ }^{3}$

Appeared in Sociological Forum, 2014

\begin{abstract}
In this paper we bring together the burgeoning qualitative literature on the socializing influence of residential colleges; the predominantly survey-based literature on campus racial climate; and the literature on diversity work in organizations, to analyze how two elite universities' approaches to diversity shape students' experiences with and feelings about diversity. We employ 77 in-depth interviews with undergraduates at two elite universities, and find that while the universities appear comparable on measures of student demographics and overall diversity infrastructure, they take different approaches. These varying approaches lead to important differences in student perspectives. At the university that takes a power analysis and minority support approach, students who participate in minority-oriented activities develop a critical race theory perspective, while their white and non-participating minority peers frequently feel alienated from that programming. At the university that takes an integration and celebration approach, most students embrace a cosmopolitan perspective, celebrating diversity while paying less attention to power and resource differences between racial groups. The findings suggest that higher education institutions can influence the race frames of students as well as their approaches to multiculturalism, with implications for their views on a variety of important diversity-related issues on campus and beyond.
\end{abstract}

Keywords: higher education, race, diversity, elite education, organizations

\footnotetext{
${ }^{1}$ The authors thank Janine de Novais, John Diamond, James Huguley, Dick Light, Julie J. Park, Julie Reuben, participants in the Harvard Graduate School of Education Cultures, Communities, and Education Workshop, and anonymous reviewers for Sociological Forum for very helpful comments and suggestions on this paper. The project was supported by the William F. Milton Fund Grant from Harvard University and the Russell Sage Foundation.

${ }^{2}$ Harvard Graduate School of Education, 6 Appian Way, $4^{\text {th }}$ Floor, Cambridge, MA 02138; email Natasha_warikoo@gse.harvard.edu

${ }^{3}$ Ithaca College, 194Q Phillips Hall, Ithaca, NY 14850; email sdeckman@ithaca.edu
} 
Educational institutions have profound influence over youth well beyond academic teaching. From gender and sexuality norms (Armstrong and Hamilton, 2013; Pascoe, 2007; Thorne, 1993) to styles of political protest (Binder and Wood, 2003), to defining acceptable ways of talking about race (Chase, 2010; Pollock, 2004), to race relations and the cultural meaning of racial identities (Carter, 2012; Tyson, 2011; Warikoo, 2010), schools and universities play a socializing role. Still, while research on the social influence of K12 education abounds, much of this work in higher education has been done by journalists (see Douthat, 2005; Kadison, and DiGeronimo, 2004; Seaman, 2007); or by education scholars with an eye toward specific questions of practice. ${ }^{4}$ Much less has been written in the domain of social life in higher education from a sociological perspective (Stevens et al., 2008; for some notable exceptions, see Armstrong and Hamilton, 2013; Binder and Wood, 2013; Nathan, 2005).

In this paper we bring together the burgeoning sociological literature on the socializing influence of residential colleges and the predominantly survey-based literature on campus racial climate to analyze how elite university campuses influence their students' experiences with and perspectives on diversity. We hone in on university "cultures of diversity” because in the United States diversity ${ }^{5}$ plays a key role in undergraduates' lives, affecting everything from admissions decisions, to where students are housed, to how universities are evaluated (Stevens and Roksa, 2011). We focus on elite institutions in particular because of their contemporary and historical

\footnotetext{
${ }^{4}$ See for example the literature on campus racial climate, which is a rich field that evaluates how specific university practices impact intergroup and interpersonal relations on campus.

${ }^{5}$ When we write of diversity we mean racial diversity. We focus on racial diversity because of its historically strong influence on elite university campuses in the United States and much of the campus discourse on diversity overall has been shaped by concerns about racial diversity.
} 
focus on fostering racially diverse campuses. Given the broad infrastructure that exists around diversity at most elite U.S. college campuses, we ask: how does this programming affect student experiences with and perspectives on race and diversity?

Through a comparison of undergraduate perspectives at two elite universities, we show that embedded in university practices and policies related to diversity are important decisions that shape student understandings of diversity on campus as well as in society. We identify two potentially conflicting approaches: (1) a power analysis and minority support approach; and (2) an integration and celebration approach. When a university takes a power analysis and minority support approach, minority students active in diversity programming on campus feel empowered by an understanding of privilege, power, and the historical roots of oppression in society, while many white students and some minority students feel alienated from diversity-related campus programming. This approach resonates with a critical race theory approach to education, in that it unpacks for participants how seemingly race-neutral policies can promote racial inequality, and in its recognition of power differences between race groups as a primary focus (Gillborn, 2006; Ladson-Billings and Tate IV, 1995). On the other hand, when a university takes an integration and celebration approach most students feel satisfied with their individual experiences with diversity, yet do not question the power differences between groups in society and the historical roots of enduring racial inequality in American society. This approach resonates with a cosmopolitan approach to civic life and diversity, which emphasizes individual choice amidst a plethora of (ethnic) group identity cultures that an individual might draw from—but only if he or she chooses to do so (Appiah, 2006). Further, varying levels of participation—and whether or not participation is mandatory or voluntary—have implications for student perspectives and race relations on campus. 


\section{Campus Racial Climate}

Harper and Hurtado (2007), in a review of research on campus racial climate, list “benefits associated with campus climates that facilitate cross-racial engagement” (p. 9) as one of three key areas of campus racial climate research. This field developed in part in response to the Bakke (1978) U.S. Supreme Court decision, which allowed for race-based affirmative action in college admissions if it is narrowly tailored and meets a compelling state interest—in this case, a diverse student body that can lead to expanded world views among all students. The decision led scholars to investigate just how a diverse student body might impact the college experience. This literature mostly takes an individual-level, quantitative approach, mapping the relationships between: (1) the number of minority students on campus; (2) interactions between students of different backgrounds; (3) institutional supports for diversity; and (4) academic, social, and attitudinal outcomes.

This body of work generally finds that there are academic and civic benefits to campus racial diversity, showing that cross-racial interactions are associated with increased interest in promoting racial understanding and increased self-reported intellectual abilities and abilities to get along with other race groups (Espenshade et al., 2009; Gurin et al., 2002; Milem et al., 2005; Sidanius et al., 2008). Beyond informal interactions, participation in diversity-related campus workshops and course content, such as courses in African American Studies or Ethnic Studies, are correlated with positive learning outcomes and increased engagement with racial issues (Gurin et al., 2002; Hurtado, 2005).

Some studies have analyzed these relationships at the institutional level to understand how campus-wide cultures, demographics, and organizational structures might influence students. For example, Chang and his colleagues (2006) find that attending a university with 
overall higher levels of cross-racial interaction is associated with more openness to diversity and self-confidence among individual students (see also Pike et al., 2007). Umbach and Kuh (2006) find that students attending liberal arts colleges are more likely to participate in diversity-related activities compared to students at other types of colleges and universities, and they feel more understanding of peers from other backgrounds.

While the above studies are important and insightful in mapping broad patterns of the impact of diversity on individuals and on aggregate among the student body, they are not able to discern how particular institutional policies and practices influence students. In other words, beyond these numbers lie complex underpinnings of the influence of diversity on campus. In order to address the mechanisms of diversity work's influence on students, we turn next to the literature on the socializing influence of residential universities, and to the literature on organizational practices around diversity.

\section{Organizations as Purveyors of Cultures of Diversity}

To help us conceptualize our study of how universities shape student experiences with and views on diversity, we turned to the burgeoning contemporary literature on the socializing influence of higher education. A growing literature demonstrates the importance of understanding higher education institutions as organizations and purveyors of culture, whether related to pathways to success or blocked mobility (Armstrong and Hamilton, 2013), styles of political protest (Binder and Wood, 2013), or understandings of race (Morning, 2011). Scholars in this small but growing field identify university cultures as well as concrete practices related to admissions, housing, and social life as influences on students' cultural outlooks (Armstrong and Hamilton, 2013; Binder and Wood, 2013; Stevens, 2007; Stuber, 2011). Still, Stevens and his colleagues (2008), in a review of The Sociology of Higher Education, point out that despite 
colleges being a key site of socialization for young adults, especially residential campuses, sociological analyses of the "experiential core of college life" are few. We contribute to this growing field by analyzing the influence of campus diversity work on students.

Other researchers have addressed the influence of diversity-related work in other kinds of organizations, such as primary and secondary schools (see Lewis, 2003; Perry, 2002; Pollock, 2004; Valenzuela, 1999); corporations (see Kalev et al., 2006); civic organizations (see Eliasoph, 1999); and diversity-trainer training (see Voyer, 2011). None of these studies, however, addresses institutional settings that systematically highlight structural racism and inequality, and only Voyer (2011) studies a context with an explicit multicultural approach.

Residential higher education — especially elite higher education—is unique among institutional settings because of the history of race-related student protest, which led to myriad changes starting in the 1960s. Elite universities were the institutional home of the New Left during the 1960s, leading to the significant diversity-related infrastructure that endures today. Student activists demanded increased numbers of black students on campus, campus centers for minority students, orientation programs for incoming minority students, changes in the curriculum, including departments for African American Studies, and more (Reuben, 2001). These institutional changes continue to influence the student experience today. (For details on the historical development of this infrastructure see Chen, 2000; Lipson, 2007; Reuben, 2001; Rojas, 2007). Today, elite private universities practice race-based affirmative action in admissions, most have a department or center for African American Studies, and many have campus centers and orientation programming related to racial diversity. More recently there has been a proliferation of administrative offices in higher education dedicated to diversity or multicultural affairs (Banerji, 2005). 
In what follows we analyze how university approaches to diversity shape student perspectives. Seemingly similar campuses and diversity-related practices can have significantly different impact on students. We show on a micro level how educational institutions can take different approaches to multiculturalism within the same national context, with important consequences for students' outlooks on diversity.

\section{Research Settings and Historical Context}

In The Distinctive College Clark (1970) outlines a historical process of colleges developing organizational identities unique to each campus; while simultaneously those identities often share elements with similar colleges (see also Pedersen and Dobbin, 2006). Similarly, Powers University and Harmony University ${ }^{6}$ are embedded in a national context that drives institutional isomorphism, especially among elite universities. During the 1960s and beyond both Powers and Harmony developed a campus diversity infrastructure in response to student protests and to maintain a sense of moral legitimacy during turbulent times. Simultaneously, the universities have taken somewhat distinct paths in the development of that infrastructure.

Powers and Harmony share much in common with each other as well as with other elite U.S. universities, which informed our decision to select them as the sites of our research. During the 1960s, students at elite universities across the United States engaged in social protest over diversity, making demands for, among other things, increased affirmative action, minority student centers, departments of African American Studies, and more (Chen, 2000; Stulberg and

\footnotetext{
${ }^{6}$ Pseudonyms are used for both universities, accompanying institutional programming and structures, and student participants. Additionally statistics are obscured, as are quotes from official university documentation. Though, all intended meaning is maintained.
} 
Chen, 2014; Rojas, 2007). More recently, elite U.S. universities seek to attract remarkably similar student bodies in terms of (1) racial and geographic diversity, (2) academic achievement, and (3) extracurricular activities (Karabel, 2005; Stevens, 2007). As a result, both Powers and Harmony have practiced race-based affirmative action since the 1960s. Six to eight percent of students at both universities identify as black; 6-9\% identify as Latino; and 11\%-16\% identify as Asian or Asian American. Additionally, both universities established programs in AfroAmerican Studies in the late 1960s. In terms of financial aid, just over 60\% of Harmony undergraduates receive need-based financial aid, as do close to half of Powers undergraduates. Lastly, in the past 10 years both universities created central university positions to address diversity, akin to the position of Chief Diversity Officer. Still, despite these similarities, which are a result of institutional isomorphism, the universities hold unique cultures of diversity. Overall, Powers takes an approach that prioritizes the needs of minority students and promotes a critical understanding of race and ethnicity in society, and Harmony takes a more integrationist approach. We outline these differences in more detail next.

\section{Powers University: A History of Activism and Administrative Response}

A group of diversity-related institutions were established at Powers University during the late 1960s and early 1970s. First, in response to student protests Powers instituted a voluntary orientation program for students of color, now called the Global South Pre-orientation Program (GSPP). Soon after, the Student of Color Peer Counseling (SCPC) Program was established, placing counselors trained in issues of racial diversity in all freshman residential halls. After SCPC was established, Powers's Center for the Global South (CGS) opened its doors, again in response to student protests. Later, in the mid-1990s, Powers was an early East Coast adopter of the Ethnic Studies major. 
These institutions remain at the core of diversity work on Powers's campus. Today there are more than twenty SCPCs who organize GSPP for over 200 incoming students every year. These institutions continue to focus on the needs of minority students. According to the Center for the Global South, GSPP's current mission is to “orient first-year students to campus resources and support services at Powers, and [to] challenge them to explore systems of oppression that are present in the United States even today.” The CGS lists four aspects of its mission, the first two of which are to serve the needs of racial minority students and to facilitate their social impact. These programs have had lasting impact today. In terms of student housing, Powers offers themed houses that students can elect to live in, including houses oriented toward African culture and Hispanic culture.

Harmony University: A History of Emphasizing Racial Integration

Historically Harmony has approached race relations from an integrationist perspective, making decisions that emphasize improving race relations between blacks and whites and foregrounding the goal of inter-cultural understanding over support for and solidarity among minority students. In terms of a campus center on diversity, the Harmony Bureau for Cross-racial Understanding was established in the early 1980s by the university president. Although Harmony minority student protesters had repeatedly demanded a minority-run center focusing specifically on the oppression of minority students, the university's administration feared signaling segregation rather than an integration mission. Today the Harmony Bureau's mandate is to "improve understanding and relations among racial and ethnic groups at Harmony in order to enhance the quality of our shared life.” Furthermore, the Bureau's mission statement notes that it sponsors regular programs and activities that are aimed at "promoting intercultural and crossracial understanding and awareness in the university community.” The mission goes on to 
highlight "the cultural contributions of students from all backgrounds." In addition to other activities, the Harmony Bureau organizes residential life programming and support around crosscultural awareness.

In terms of first-year orientation, Harmony students are required to participate in “Community Talk," a small-group discussion on racial and class diversity. Community Talk is mandatory for first-year students and is held during freshman orientation. There is no separate orientation for minority students analogous to Powers's GSPP.

In contrast to Powers's ethnic-themed housing options, Harmony switched its housing policy in the early 2000s from one in which students were assigned to dormitories based on preference to random housing assignments. The switch to randomized housing assignments came on the heels of perceptions of racial segregation on Harmony's campus. Thus, the change was intended to promote racial diversity in Harmony’s dorms. One dean has said that randomized housing "is a good example of an [administrative] policy that supports [the university's] value of diversity.” Harmony administrators also deliberately craft diverse freshmen rooms and suites through a complex matching process. Finally, in terms of course offerings, in the early 2010s Ethnic Studies was established as a minor at Harmony.

Overall, Harmony focuses on supporting racial integration, with less emphasis on providing minority students separate spaces to develop racial identities and consider racial oppression. On the other hand, the portrait above shows the significant emphasis that Powers University places on supporting minority students and their racial and ethnic identities, by providing opportunities to develop in-group solidarity and to confront racial oppression. We call Harmony's an integration and celebration approach and Powers's a power analysis and minority support approach. Our analysis reveals how the different approaches of Powers and Harmony 
impact student experiences and perspectives. Students at Harmony expressed more satisfaction with campus diversity and less critique of systemic issues of inequality. Students at Powers active in diversity programming developed in-group solidarity and discursive tools to confront racial inequality, while their peers who did not participate-mostly white students and some students of color-expressed dissatisfaction and disagreement with the racial separation they perceived.

\section{Methods}

The findings presented in this paper emerged from a larger study of undergraduates at elite universities and their understandings of merit, inequality, and diversity. In this paper we employ 77, one-on-one, in-depth interviews with undergraduates attending Powers University and Harmony University. Interviews were a particularly apt tool in our research, which is concerned with understanding the meaning students make of their experiences with campus diversity (see Seidman, 2006). Further, the qualitative and comparative approach we took to conducting this work contributes a deeper understanding of the influences on students’ perspectives as well as the complexity of those perspectives on diversity than is possible with survey data.

All but two students interviewed were in their second year or later (the remaining two were second-semester freshmen), to ensure they had ample campus experiences to draw upon. Interviews lasted one to three hours, with an average of 120 minutes. Students were paid \$20 for their participation. At both sites 23 white students and 15-16 students of color were interviewed. Among the 31 students of color, 17 were black, Latino, or Native American, and 14 were Asian. All participants were U.S.-born or arrived to the United States before age six. In this paper we focus on student responses to questions about campus life in order to identify student 
perspectives on campus diversity and the experiences that shape those perspectives.

Students were recruited through emails to 16 residential halls at Powers (approximately 400 students) and to one residential house at Harmony (350 to 500 students) to which students are randomly assigned. ${ }^{7}$ The recruiting email indicated that the project compares the university experiences of students at elite universities in the U.S. and Britain, with an emphasis on issues related to diversity. All eligible students who responded to the recruitment email were included in the study. After being interviewed students were asked to pass along our details to acquaintances living in the same dorm. White men were slightly underrepresented in our original sample; we consequently sent a message specifically requesting white men to sign up, which was a successful strategy for broadening our pool. We compared pre-interview survey responses to available data on the student bodies at Powers and Harmony related to field of study, type of high school attended (private, parochial, or public), and parental education, and found percentages to be similar. This bolstered our confidence that overall our interview respondents did not differ from their peers on campus in fundamental ways. Still, while our recruitment techniques did attempt to capture a diverse range of student perspectives, we want to emphasize that our sampling is not meant to be a stratified or random sample.

Two minority doctoral students interviewed students of color (one on each campus), and a white doctoral student interviewed all white students, with the belief being that student participants would be likelier to share their views on race and diversity with an interviewer with whom they felt a shared sense of background (Hammersley and Atkinson, 1995). All interviews were conducted in 2010 and early 2011. We analyzed interview transcripts using ATLASti,

\footnotetext{
${ }^{7}$ Residential halls did not include ethnic- or race-themed halls, nor residential fraternities or sororities, in order to maximize the variation among students’ perspectives we include.
} 
coding data for repeated words, references, and themes (Charmaz, 2006; Lofland and Lofland, 1995). Campus diversity centers and diversity-related orientation events came up repeatedly across the interviews when students discussed the impact of diversity on campus life and thus formed the basis for the inquiry presented in this paper.

\section{Findings: Student Voices on Institutions of Diversity in Elite Higher Education}

We found that $83 \%$ of students at both universities overall describe diversity favorably. The data confirm that diversity is very much a part of the elite university curriculum in the United States (see also Stevens, 2007). This similarity between Powers and Harmony contrasts sharply with Author 1's (n.d.) findings in Britain at a similarly elite university, where there was much less talk of diversity, either positively or negatively. One Harmony student, a senior social science major, in fact claimed that "diversity is the essence of Harmony life,” adding,

Every day here is just about, like, millions of activities by different groups. I think

[Harmony] is the place where cultures are always coming together and people are...doing things with their own culture but also exposing everyone else at Harmony to it. Indeed, over $80 \%$ of students on both campuses told us they had attended a diversity-related event on campus, whether required or voluntary. If not confirming the value placed on diversity, the frequent attendance at diversity-related events at least demonstrates the prevalence of and student interest in diversity-related programming.

Further, many students at both universities explicitly described increased acceptance of and value for diversity and multiculturalism through their campus experiences. For example, James, a white junior majoring in the social sciences at Powers, noted,

Coming here, I have a lot more respect for multiculturalism. As far as diversity goes, like when people said, “Powers has a lot of diversity,” I didn’t really care about that. I 
[thought it was] just a college. And since I’ve been here, I think it’s really important. During his interview James highlighted his two college summers spent abroad as well as his roommate group, comprised of both white and Asian students, as influencing his view. He also attended a CGS workshop, "White Allies," in which he discussed "notion[s] of whiteness.” This workshop helped inform James' views on what it means to be white in U.S. society and prompted him to call for more opportunities for students to engage in similar conversations across different racial groups.

Diversity is also seen to be very much a part of the learning process at both universities. The educational value of diversity is the sole argument for affirmative action that has been repeatedly upheld by the U.S. Supreme Court (Grutter v. Bollinger et al., 2003; Regents of the University of California v. Bakke, 1978). Students believed in the educational value of diversity and used that frame ${ }^{8}$ frequently. When asked how diversity has enhanced life at Powers, James, the junior quoted above, shared a perspective that resonated with many of his colleagues' responses: "You get a lot of different viewpoints." One Harmony student, Thomas, a white sophomore science major, reported that "diversity is really how you learn here. I mean, you can take as many classes as you want but your peers are your best teachers.” In terms of classes, just over one-third of students on both campuses specifically took classes in African American/Pan-

\footnotetext{
${ }^{8}$ Small and his colleagues (2010) define cultural frames as lenses "through which we observe and interpret life...A frame structures how we interpret events and therefore how we react to them," (pp. 14-15). Frames impact the interpretation of social phenomena, by making certain aspects prominent and obscuring others.
} 
African Studies or Ethnic Studies. ${ }^{9}$ Hence, students at both universities expressed positive associations with diversity on campus in a general sense, and in particular noted benefits from the variety of voices that diversity brings to their classrooms and social conversations at college.

Still, we found many stark differences in the experiences of students on each campus. Whereas diversity is seen to have intrinsic personal and educational value across our participants, what they understood valuing diversity to mean turned out to be very different, and these different meanings corresponded to campus structures put in place to institutionalize diversityrelated work. In the next section we report on differences in two particular aspects of campus life—orientation events on diversity, and campus centers for diversity—and the impact of these differences on students' experiences with and understandings of diversity. We focus on orientation events and campus centers rather than, for example, coursework in Ethnic or African American Studies, because these are areas driven largely by the university administration as a whole rather than individual faculty or academic disciplinary trends. This allows us to unpack the overall influence of the different approaches to diversity on students, aside from particular courses or non-university experiences.

\section{Diversity Training at Orientation and Beyond}

Both Powers and Harmony host freshman orientation events around diversity, a finding which emerged from an interview question asking students if they had attended any diversityrelated workshops on campus. Powers hosts a separate, voluntary half-week "Global South Preorientation Program" (GSPP) that is open to all students but is attended primarily by students of

${ }^{9}$ Similarly, Espenshade and his colleagues (2009) found that $40 \%$ of students attending eight of the top colleges/universities in the United States have taken at least one course in African American, Asian American, or Latino studies (p. 178). 
color, with approximately $10 \%$ of entering students of color along with a handful of white students attending GSPP every year, while all Harmony students are required to participate in a 90-minute "Community Talk" during freshman orientation. Though the programs are sponsored by their respective universities in order to address issues of campus diversity, Community Talk and GSPP were viewed quite differently by students. While GSPP participants usually experienced profound personal developments and gained deeper understandings of the world, non-participating students expressed strong concerns that GSPP separates students of color from white students from the outset of their college experience. Community Talks at Harmony, on the other hand, were less polarizing among our study participants, perhaps because they were mandatory for all students. However, many students reported Community Talks to have a limited impact on their views or in forging meaningful relationships or discussions among students of different backgrounds.

Global South Pre-orientation Program (GSPP) at Powers University: Influential, yet Polarizing GSPP focuses not only on student support, but also, according to the program's informational materials, on "systems of oppression that exist in our society...[such as] racism, classism, sexism, and heterosexism.” The program maintains a particular focus on communities of color at Powers, but also emphasizes coming together across difference as a goal and outcome of GSPP. GSPP informational materials state that "through examining problems that divide our society, [GSPP aims to] break down barriers that separate us with the goal of building understanding and community.” Through its emphasis on power and inequality, GSPP promotes a social justice frame for understanding race in society. A social justice frame, employing the analytical tools of critical race theory, recognizes the power differences between race groups in society, and it emphasizes the ways that power operates through racial inequality (see also 
Feagin, 2006).

Five of our seven respondents who had attended GSPP praised it enthusiastically. ${ }^{10}$ These students reported that GSPP gave them a vocabulary to discuss societal ills and allowed them to make a diverse group of friends because of the pan-ethnic nature of the program. For Nisha, a South Asian junior who was majoring in social sciences, GSPP presented the first time she had been invited to think critically about social inequality and oppression. Nisha said, “...if you have never been presented with all these ideas of colonialism and imperialism, and how they affect you, and you're suddenly like, whoa! [laughs] Here I was just chilling and going to college, and all of a sudden, my worldview is rocked.” Though Nisha did say the GSPP experience can be “overwhelming," she also noted that she "loves” having had the opportunity to engage with these issues.

Even students who had spent time before college engaged in discussing or otherwise thinking about the issues covered at GSPP found the experience illuminating. Ekene, a selfidentified black and multi-racial, senior social science major, said the experience was "life changing.” She explained that talking about "racism classism, sexism, heterosexism, homophobia, imperialism” at GSPP helped her develop a vocabulary for discussing racism, ...Race is something I've thought about a lot and that's been really important to me throughout my life, but coming to GSPP...gave me a vocabulary to talk about it, and that was key... It really, like, concretely explained the difference between interpersonal racism and institutional racism...It just all started to click and make sense.

\footnotetext{
${ }^{10}$ One of the two dissenters was a white student who expressed ambivalence about the valorization—as he perceived it—of oppression at TWTP. The other was a black student who felt TWTP fostered segregation and focused too much on racism rather than integration.
} 
Ekene also found these discussions to support community building. She explained, The other [important] piece, I think, was that [GSPP] was led by students and it was in the context of forming real connections with people...We're not just talking about these issues, but we're trying to build a community.

Jessica, a Latina social science major, shared this view, describing her experience with GSPP, "I went through GSPP...so that's where I met most of my friends. They're people from all over...All different races, cultures, ethnicities, and we're all friends.” Interestingly, although Jessica points to her experience with making friends of diverse racial and ethnic backgrounds at GSPP, many white students criticized GSPP for segregating the campus and preventing them from entering friendships with students of color who, they assumed, already formed their friendships during GSPP. This demonstrates a key difference in understanding diversity between participants and non-participants. Non-participants, especially those who are white, viewed groups of students of color as homogenous or self-segregating, while minority participants themselves viewed the pan-minority program as diverse and a means toward coalition-building across racial lines.

Overall, then, GSPP takes an uncommon approach to diversity training. Voyer (2011) finds that most corporate and non-profit diversity training emphasizes intercultural sensitivity at an individual level, ignoring institutionalized privilege and inequality in society. In contrast, GSPP addresses both interpersonal as well as institutionalized power and resource differences between groups in society, which reorients the worldviews of many participants in transformative ways. It thus leads many participants to a social justice frame.

In contrast to the praise, many non-participants critiqued GSPP. Overall, 38\% of white students (including one respondent who attended GSPP) and one-third of students of color 
(including one attendee) expressed critiques of the program. There were two consistent critiques of GSPP among Powers students of all racial backgrounds: (1) it creates divisions between students of color and white students, because white students are thought to be excluded ${ }^{11}$, and (2) GSPP inappropriately assumes commonality among students simply because of a shared minority background. There were a number of other concerns that weren't shared as widely across students, including that GSPP leads to a sentiment on campus that feeling oppressed is "cool," akin to a status marker, and that its focus on race is misdirected. While GSPP was recognized by many students as a university-sponsored “diversity workshop" experience, many also spoke about GSPP in response to the interview question "Do students of different ethnic and racial backgrounds at Powers mix, in general?” and follow up questions about the extent to which groups “self-segregate.”

By far the biggest concern across Powers students was that GSPP created racial divisions among students. This critique had less to do with the structure and topic of the GSPP workshops and more to do with whom the students perceived to be the target audience of and participants in GSPP. There was a sense from many white Powers students that GSPP deprived them of potential friendships with their peers of color. One white sophomore, Jeff, a math major, explained this concern in detail,

I have a lot of problems with [GSPP] because again it assumes that people have more in common...with...people who have the same skin color as them, and people who have the same background. Powers sends invitations to anyone who like checked off a non-white box in the right section of the application. So...it has a really real effect of creating fault lines across races in the university...It makes it so that all the students who went to

\footnotetext{
${ }^{11}$ This is a misperception. White students are not barred from participation.
} 
[GSPP] got to know each other a week before anyone else came to campus. So when most people come onto campus, the rest of the Powers student body... these people already have a friend group...Those groups have persisted even into sophomore year. Jeff acknowledges that "everyone’s welcome [at GSPP]. But...there very rarely are Caucasian people who go to GSPP.” Hence, while GSPP participants saw the program as supporting crossracial alliances, non-participants saw it precisely as the opposite. For participants the racial boundaries emphasized were between minority groups, while for non-participants the boundary emphasized was minority-white. Present in Jeff's view—exceedingly common among the white students interviewed at Powers—is the underlying notion that friendships with students of color are a university resource that white students are unfairly deprived of given the universitysponsored GSPP.

The critiques of GSPP were not limited to white students. Kelly, an Asian American junior who was majoring in humanities and did not attend GSPP, called GSPP and similar programs “polarizing." She noted, GSPP is

...mostly for people who are non-white to come and discuss racial issues. I didn’t attend, but I have heard that it's more like discussing the white problem... I am friends with a lot of people who've done this program and...just because it starts before school officially starts, so it's kind of like, it's building your community of friends and your networkyour relationships—-before you get to interact with white people at Powers.

In Kelly's view GSPP led to problematic separation between students of color and white students at the start of their college careers. Kelly believed that the focus of university sponsored programs meant to "maintain...community" and "promoting diversity" should instead focus on 
“accepting” rather than "promoting” diversity. ${ }^{12}$

Student reactions suggest a polarizing effect of GSPP, whereby most attendees-mostly students of color-experienced profound, life-changing experiences, while many non-attendees, both students of color and white students, held critical views of the program and viewed it as a source for campus division along racial lines. Those who appreciated the program described the vocabulary, recognition of disadvantaged status and multi-racial community that develops through the program, as well as GSPP's significant impact on their worldviews. On the other hand, critics resented the campus division between students of color and white students that they perceived to be a result of students of color forming their friendships among each other at GSPP prior to white students’ arrival on campus. Powers’s power analysis and minority support approach empowered minority students who underwent its training through a social justice race frame—initiated through GSPP—while it alienated some non-participants, who were predominantly white students on campus, perhaps because of its implicit need for minority-only discussions as well as its emphasis on oppression and power differences, which highlights white privilege and hence might incite white guilt.

Community Talks at Harmony: Limited Impact Harmony’s Community Talks are mandatory 90-minute discussions for all incoming

\footnotetext{
${ }^{12}$ Asian Americans in elite higher education share some experiences with white students, and others with their black and Latino peers. For example, while the GSPP and CGS include Asian Americans in the racial minority experience, fostering a pan-minority identity, discussions about admissions to elite universities note the possibility of an "Asian penalty,” given that Asian American students have higher average SAT scores than their white, black, and Latino peers at elite universities (Espenshade et al., 2009).
} 
students, facilitated by a variety of faculty members, administrators, and staff. The university describes the goal of the discussions as a vehicle to build a cohesive and inclusive community in addition to promoting conversations about diversity. Although in preparation for the discussions students are asked to engage with issues related to diversity by reading provocative pieces by authors such as Beverly Daniel Tatum, respondents who brought up Community Talks generally described the discussions as dissatisfying and not influential. Three white students and seven students of color from Harmony (26\% of respondents) mentioned Community Talks in their interviews, either spontaneously or in response to the question "Have you attended any diversityrelated workshops at Harvard?” Given that the vast majority of students likely did attend given that participation is mandatory and monitored, this low rate of reporting suggests that the conversation did not make a strong impression on participants. In addition, all white students who mentioned the Community Talks expressed dissatisfaction with them, as did two of the students of color.

Even some of those who did mention Community Talks did not remember much. When asked if he had ever attended any diversity-related workshops at Harmony, David, a Chinese American sophomore science major, responded,

In freshman year, we had to go to, I forget what they were called, something talks. They were required....We read some packet, I forgot what was in the reading... I barely... I remember I went to this room, and we had two residential advisors who came in and they led the discussion. I feel like the discussion... didn’t play that major a role in my life because I don’t really remember it.

Some who did recall their participation in Community Talks described the session as feeling forced and having a limited impact on their views. Grace, a Korean American sophomore 
majoring in social sciences, remembered the session as "bizarre" and "overdoing it." She said, I don't think it really affected me.... I just saw how people felt about having to go to this required conversation, and what people were saying about the readings that we had. In general, the attitude was like, "Why do we have to do this? This is really stupid." And other people were like, “These readings are very loaded... They’re leading us, and it’s very obvious.” Obviously they want us to think a certain way, and because they want us to think a certain way some people will resent that.

Grace identifies the problem with Community Talks as being required, leading students to view them as an imposition—and perhaps even indoctrination. Grace also suggests that even wellintentioned diversity efforts can backfire depending on the implementation.

The university relies on numerous facilitators in order to run the mandatory Community Talks for all first-year students at the same time during a full orientation schedule. This leads to some variation in the race frames that facilitators present. Brianna, a white sophomore majoring in humanities, found her session for Community Talks to be problematically facilitated. Brianna believed that her session's facilitator was "biased." She offered the following anecdote as proof, He [told] us this story about how Harmony University police are racist, because he was walking once and he went to go into a building and a police officer asked to see his ID. He made that out to be this horrible thing ... And I mean, even so, if that one police officer was racist... it doesn’t mean all Harmony police are racist....

Brianna goes on to say, “I didn’t have any black roommates—but all my other roommates were kind of like, 'yeah, he’s kind of against white people.’” It may be the case that Brianna expected an integration and celebration approach to the Community Talk, especially since all students were required to participate, while her facilitator may have assumed a power analysis and 
minority support approach, without the time to fully develop students' understandings of how power operates to support racial inequality in American society. In contrast, the voluntary GSPP at Powers is run entirely by students who undergo a minimum of five days of training for the workshop that lasts four full days. This is made possible by having just a small number of the incoming cohort participate.

Overall, then, Community Talks, a campus initiative meant to "promote communication across difference" through an integration approach may not be having the intended impact on students. The integration approach requires that all students participate, but a more extended discussion may not be feasible during an action-packed orientation schedule. Furthermore, some students resented even the 90-minute time period for a discussion of diversity.

In this section we have shown that although Powers and Harmony both host diversityrelated workshops for incoming undergraduates, their influence on students is distinct. Powers's model emphasizes affirmation, solidarity, and resilience-building for students of color. Harmony's integration and celebration model has the potential to foster campus-wide integration and unity, generally promoting a diversity frame in which race differences are seen as embodying cultural differences to be celebrated. Under this diversity frame, cultural identities are meant to be chosen and optional; in this way, they are ultimately embedded in a cosmopolitan perspective, rather than a pluralist multiculturalism (Hartmann and Gerteis, 2005). On the other hand, Powers's GSPP seems to have a polarizing effect, such that most participants report profound shifts in their worldviews, improved communication skills for discussing social inequity and injustice, and abilities to build communities across racial lines with other participants, while many non-participants express strong opposition to the program, which they feel segregates student friendship circles by race and reifies racial differences. In the same vein, 
at Harmony, students looked back at their orientation Community Talks with ambivalence, many forgetting what had transpired in those short sessions. Many of those who remembered, resented the compulsory aspect of the discussions, and some wished for better facilitation.

\section{Campus Centers}

Another way in which students engaged with diversity-related issues on an institutional level was through campus centers—specifically Powers's Center for the Global South (CGS) and the Harmony Bureau for Cross-racial Understanding. Both centers are well-known on their respective campuses, with 53\% of Powers interviewees bringing up the CGS in their interviews (12 of 15 students of color and 8 of 23 white students) and 38\% of Harmony students discussing the Bureau in their interviews (9 of 16 students of color and 6 of 23 white students).

Both centers offer an array of programming throughout the year. The Harmony Bureau, for example, not only supports residential programming, described above, but also puts on a number of small and large events each year on the Harmony campus that focus primarily on celebrating intercultural communication and understanding, such as a visual arts exhibit, and a cultural festival including food and performance that is one of the largest events on campus each year. Harmony's integration and celebration approach is most visible in the work of the Harmony Bureau. Meanwhile, Powers's CGS claims a four-part mission, including three goals related to supporting minority students and their community impact, and one related to increasing social awareness on campus and in society. As such, the CGS focuses on events that recognize the heritage of minority students and particular cultural groups through a program series focused on Latinos, multiracials, Asian/Asian Americans, blacks and Native Americans. The other flagship programming at the CGS includes the Global South Pre-orientation Program (GSPP), as well as the Student of Color Peer Counselor program (SCPC), both described above. 
As with students' experiences in diversity-related workshops, experiences differ greatly between the two campuses. In this case, Powers students were again divided on their assessments of the CGS, with some criticizing the center and others describing transformative experiences, while Harmony students tended to praise the intercultural efforts of the Harmony Bureau. Powers's Center for Global South: A Controversial Power Analysis and Minority Support Role

Among Powers students who mentioned the CGS in their interviews, students of color were likeliest to unequivocally praise the center (7 of 13 students), including naming it as a support for students of color on campus, while white students were likelier to express ambivalence about the center, noting that it served as a support for students of color but excluded white students (4 of 7 students). Many of these views were shared in the section above on orientation programming in the GSPP section. Primary points of praise for the CGS included that it served as a support for students of color and promoted understanding across cultures, while those who critiqued the center argued that it was a source of divisions among students.

Among those who praised the CGS as a means by which Powers actively supports students of color and promotes multiculturalism was Sarah, a white social science major. Sarah had this to say about the CGS, "[Powers has] the CGS, which encourages multiculturalism and minority groups to make their mark on campus and to also connect with one another and share similar experiences and backgrounds to create a more comfortable environment.” Susan, a black junior who had served as a Student of Color Peer Counselor (SCPC) shared this view, I do a lot of work with the CGS and that's sort of all about bringing people of diverse backgrounds together. So I think multiculturalism and diversity is really stressed at Powers, especially in that space. But Powers is also a predominantly white institution and sometimes it's surprising how few people of color there are in certain places. 
Both Sarah's and Susan's comments suggest a need for understanding the particular, sometimes challenging, position of students of color at predominantly white institutions, taking into consideration the historical absence of minority students and faculty at institutions like Powers. Both also see the CGS as serving as a necessary support for such students. This power analysis and minority support approach recognizes the difference in power and visibility between white and minority students on campus, and consequently the need to have minority-specific supports in place to contravene those differences.

Conversely, others argued that the CGS has done more to promote racial division than cross-cultural understanding. Some students commented that the focus on race and racism is misplaced because, for example, "I really don't see any racism on campus. And I think that the amount of focus that's being paid to it is kind of disproportionate.” This student, Jeff, a white math major, said of the SCPC program that is run through the CGS, "I do see some inherent classism at Powers and I feel like it would be better if the role of the SCPC evolved to focus more on that.” Students like Jeff preferred an integration and celebration approach to diversity, claiming that racial inequality is driven exclusively by class inequality.

Some students claimed that CGS programming is aimed only at students of color and therefore a divisive force on campus. For example, Sarah, the white social science major quoted above, explained,

I think a lot of kids take issue with perceived self-segregation [of the CGS]. They say, "Well I understand why it was created in the '60s and the '70s to promote more acceptance, diversity, and solidarity. But now, shouldn’t the campus just be open? And if you're creating these programs for only one group of people, isn't that out of necessity creating division?”....I think the emphasis should be less on sort of solidarity and 
creating the separation, but rather... sharing one's culture or background....

Like Sarah, many white students believed that the structure of the CGS prevented it from benefitting white students, which contravened their diversity frame for understanding race on campus. In other words, because of the emphasis on supporting ethnic and racial identities, the lack of focus on integration left white students feeling like they had few avenues to engage students of color on diversity-related issues. This left them frustrated, perhaps in part because the dominant ideology in higher education emphasizes the educational value of diversity on campus for all students, yet the students perceived the CGS to separate white students from their minority peers. Contributing to the feeling of exclusion is the space allocation of the CGS. Jenny, an Asian American and white biracial student, said, ...upstairs they have a room for every minority. They have a room for African Americans, a room for Hispanics, and a room for Asians. And that doesn’t sit well with a lot of people here.

Although Jenny is biracial, this kind of critique came most frequently from white students. ${ }^{13}$ The sentiments they express suggest that they are uncomfortable with and opposed to the perceived segregation of the CGS's structure-much like the critiques of the GSPP orientation programin spite of their awareness that all students are welcome to attend CGS events and to utilize the space. Furthermore, they suggest that many white students would prefer that the CGS focus more on racial and ethnic integration rather than on activities that, as they perceive it, segregate the student body. That is, they might prefer an integration and celebration approach.

\footnotetext{
${ }^{13}$ It may be unsurprising that the students of color who tended to level this critique of the CGS identified as biracial. Smith and Moore (2000) find that biracial college students may feel more social distance from and less closeness with their mono-racial peers of color.
} 


\section{Harmony Bureau: Integration and Celebration through the Arts}

In stark contrast to Powers students' discussion of the CGS, almost all Harmony students praised the work of the Harmony Bureau as one way the university supports multiculturalism. When discussing ways in which diversity has enhanced life on campus, a number of students discussed Unity Fest, the largest student-run event at Harmony each year, which is sponsored by the Harmony Bureau and run by Bureau student interns. Unity Fest includes a performance showcase where students dance, play music, and perform martial arts from various cultural heritages. The day-long event also includes a food festival as well as performance showcases.

One student who praised Unity Fest was Tim, a white sophomore social science major. When asked how diversity has enhanced life at Harmony, Tim replied, “There’s cultural shows and events that people from different backgrounds throw that the WASPy culture of yesteryear definitely would not...have been exposed to. I think that’s good.” He spoke specifically about Unity Fest, “I think it’s good. It exposes people to what the real world is like.” In Tim’s view, that students can see others engaged in cultural performances gives a glimpse into the "real world.” Other students enjoyed the food festival component of Unity Fest. Thomas, one such student, a white sophomore studying science, said, "Unity Fest was a lot of different ethnic groups' food, and that was great because I love food. It was stuff I’d never had before.”

Only one student, Jeremy, a white senior humanities major, offered a view that was explicitly critical of Unity Fest, which in his view was an "empty gesture.” We asked Jeremy if he sees evidence of multiculturalism at Harmony,

Not really. I see people trying, but a lot of the things they do to try are clearly very empty gestures. Like, they'll have shows...like Unity Fest, for example....So they have all the different cultural organizations put on their little dances for everyone and, like, “Oh, look 
how wonderful culture at Harmony is!” But...it strikes me as empty mannerisms adopted to give one a sense of belonging in a place that's actually very homogenous. Jeremy's views are in direct contradiction with Tim's: where the former saw “empty gestures,” the latter saw the "real world" through Unity Fest. Jeremy’s views were, however, anomalous among our participants.

Whereas one of the criticisms of the CGS by Powers students was its divisiveness, multiple Harmony students explicitly offered the view that Unity Fest actually works to bring communities together. To illustrate this point, Genevieve, a white social science major, said, Unity Fest is sponsored by the Harmony Bureau, rather than a specific ethnic group. So I think that's a good example of where the existence of ethnic-specific groups really does foster a collective appreciation for diversity....There's a thousand people who come, and you get to see the South African dance team... and the Irish step dancers. All the groups perform together on one stage. So for me, that's a beautiful and a powerful picture of the tremendous artistic creativity that every one of these minority groups brings to America. Genevieve emphasizes the expanded perspective she gains through diverse encounters, and she embraces the integration and celebration approach of Unity Fest.

Considering Genevieve's view, it is interesting to note the differences in approach of the CGS and the Harmony Bureau. The key CGS programming focuses on having students engage in discussions about societal issues such as racism and classism, whereas the Harmony Bureau's key programming focuses on cross-cultural exchange through the arts. Our data suggest that students generally and white students specifically are more comfortable engaging with the latter as opposed to the former. On one hand, this may speak to the transformative power of the arts in terms of crossing racial and cultural boundaries. At the same time, it is also possible that the arts 
are a more appealing venue for students as they are not necessarily forced to directly confront social disparities. Though many Harmony students noted that they appreciated the glimpse of diversity that the Harmony Bureau provides through Unity Fest, few mentioned that attending the event significantly impacted their views. Conversely, our Powers participants, while divided about the role of the CGS, were engaged in debates about diversity on campus and in society, questioning systemic inequality, given the presence and activities of the center. Both uniting students through multicultural events and engaging them in serious debates about issues of diversity can play important roles in students' experiences of campus diversity. However, as we have shown in this section, the differing approaches of campus centers at Harmony and Powers have different impacts on ultimately shaping students views.

\section{Discussion}

Our findings have shown that well beyond the numbers and basic institutional structures, seemingly similar universities in terms of demographic measures of diversity can have different influences on students. Powers's power analysis and minority support approach leads to a strong community among students of color who take part in activities sponsored by the CGS and a social justice frame for understanding race among those students, as well as a heightened awareness of race. Students engage, head-on, complex questions of race, inequality, and social justice. This has benefits especially for students of color, many of whom gain a critical perspective on their own socially-situated experiences and the unequal institutional structures in the United States today. On the other hand, this approach's emphasis on racial identities draws attention to, and may exacerbate differences between, minority and white students, and sometimes alienates white students, who feel excluded from the dialogue and community this approach engenders. 
Harmony employs a different model—integration and celebration—which focuses on commonalities across groups in order to build solidarity across racial lines, and promotes a diversity frame on race among students, including all students in conversations and celebrations about diversity. The university thus avoids activities that might draw attention to and reinforce racial separation, and instead focuses on building unity, with a cosmopolitan approach. By doing so, this approach may provide less space for students to critically engage questions of inequality, racial discrimination, and power at a deep level. While an integration and celebration approach will view some initiatives as divisive, the power analysis and minority support approach is less concerned with campus division.

Our interviews suggest that these two approaches result in different campus experiences for students. Harmony undergraduates overall report less dramatic changes in their perspectives on diversity and multiculturalism through their campus experiences during orientation and campus diversity centers compared to Powers undergraduates, even while Harmony’s orientation workshop is mandatory, and the campus center focuses on drawing in students of all backgrounds. The integration and celebration approach shows promise because the university is not manufacturing a crisis in terms of diversity issues on campus, but at the same time the university may not get at some of the real issues that need addressing and student identities that need affirming in a majority culture, elite environment. On the other hand, the power analysis and minority support approach may lead many white students to experience frustration and dissatisfaction with a perceived polarizing effect of diversity-related programming and institutions. The benefits of this approach can be juxtaposed with the cost of the divisiveness that some of the programming creates.

Overall, the findings above show that a qualitative approach can help to elucidate the 
mechanisms by which seemingly similar practices in educational institutions-like orientation events and diversity-related centers_ — can have important differences in impact based on the details of those practices. Our qualitative approach extends the findings of survey-based research analyzing how and when interracial interactions on an individual level and overall on campus influence students’ perspectives on racial difference, by demonstrating the importance of understanding the campus approach to diversity. Further, we show how institutions can shape the race frames that individuals embedded in those institutions hold-hence we demonstrate the malleability of race frames. The findings resonate with research by Kalev and her colleagues (2006) that shows the kinds of diversity-related activities in which businesses engage have a strong influence on whether or not those activities are associated with organizational change. More generally, our findings contribute to the literature on the socializing influence of higher education by demonstrating the power of residential, elite higher education institutions to shape students’ perspectives on diversity. We highlight two different approaches to cultures of diversity on similar campuses. Through our qualitative, cross-institution analysis, we are able to unpack the ways that campus diversity programming shapes both race relations on campus and students’ race frames.

Finally, although most of the literature on multiculturalism emphasizes national-level models for dealing with diversity in society and how these vary across national borders (for example, see Brubaker, 2001; Joppke, 2004), we demonstrate a case of different practices around diversity within the same national context and between similar universities. This suggests that institutions — specifically, in our case, higher education institutions — have an important role to play in developing their students' frames around diversity, inequality, and group identities.

As universities consider diversity-related programming, it is important to keep these two 
models in mind. It may be the case that not all diversity-related goals and outcomes, as measured by previous research, are compatible. If this is the case, then universities need to carefully deliberate on which goals they are furthering in diversity-related programming. How, then, can other universities learn from these two elite universities? The answer to this question depends on institutional goals. If a university seeks to implement strategies for developing self-confidence, solidarity, and resilience among students of color, it should draw from the power analysis and minority support model. On the other hand, if a campus is concerned with campus division between white students and students of color, it should draw from the integration and celebration model. Still, the real challenge, we contend, is to develop a model that can incorporate both of these worthy goals. Both students of color and white students need to think deeply and critically about racial inequality, discrimination, social justice, and power. They both also need to develop tools for engagement and dialogue across racial lines, in order to fully take advantage of their deliberately racially integrated campuses. Perhaps one model for this is Gurin and her colleagues' (2013) model of intergroup dialogue, which integrates social psychological research suggesting that intergroup harmony requires downplaying group identities or shifting group identities (for example, from racial identities to dorm identities) with Tajfel's (1974) argument that strong group identities can be a basis for social change and hence are important and necessary. Future research should analyze this work for its impact on race relations on campus and for student understandings of inequality. 


\section{References}

Appiah, Kwame A. 2006. Cosmopolitanism: Ethics in a World of Strangers. New York: W.W. Norton \& Co.

Armstrong, Elizabeth A., and Laura T. Hamilton. 2013. Paying for the Party: How College Maintains Inequality. Cambridge, MA: Harvard University Press

Banerji, Shilpa. 2005. “Diversity Officers-Coming to a Campus Near You?” Diverse: Issues in Higher Education 22: 20: 38-40.

Binder, Amy J., and Kate Wood. 2012. Becoming Right: How Campuses Shape Young Conservatives. Princeton, NJ: Princeton University Press.

Brubaker, Rogers. 2001. “The Return of Assimilation? Changing Perspectives on Immigration and Its Sequels in France, Germany, and the United States.” Ethnic and Racial Studies 24: 531-548.

Carter, Prudence. 2012. Stubborn Roots: Race, Culture, and Inequality in U.S. and South African Schools. New York: Oxford University Press.

Charmaz, Kathy. 2006. Constructing Grounded Theory. Thousand Oaks, CA: Sage Publications.

Chase, Susan E. 2010. Learning to Speak, Learning to Listen: How Diversity Works on Campus. Ithaca: Cornell University Press.

Chen, Shu-Ling. 2000. “Debates over Third World Centers at Princeton, Brown and Harvard: Minority Student Activism and Institutional Responses in the 1960s and 1970s.” Unpublished Ed.D. Dissertation, Graduate School of Education, Harvard University, Cambridge, MA.

Clark, Burton R. 1970. The Distinctive College: Antioch, Reed \& Swarthmore. Chicago: Aldine Publishing Company.

Douthat, Ross Gregory. 2005. Privilege: Harvard and the Education of the Ruling Class. New 
York: Hyperion.

Eliasoph, Nina. 1999. “'Everyday Racism’ in a Culture of Political Avoidance: Civil Society, Speech, and Taboo.” Social Problems 46: 4: 479-502.

Espenshade, Thomas J., Alexandria Radford Walton, and Chang Young Chung. 2009. No Longer Separate, Not Yet Equal: Race and Class in Elite College Admission and Campus Life. Princeton, NJ: Princeton University Press.

Feagin, Joe R. 2006. Systemic Racism: A Theory of Oppression. New York: Routledge. Gillborn, David. 2006. “Critical Race Theory and Education: Racism and Anti-racism in Educational Theory and Praxis.” Discourse: Studies in the Cultural Politics of Education 27: 1: $11-32$.

Grutter v. Bollinger et al., 539 U.S. 306 C.F.R. 2003.

Gurin, Patricia, Eric L. Dey, Sylvia Hurtado, and Gerald Gurin. 2002. “Diversity and Higher Education: Theory and Impact on Educational Outcomes.” Harvard Educational Review 72: 3: 330-366.

Gurin, Patricia, Biren (Ratnesh) A. Nagda, and Ximena Zúñiga. 2013. Dialogue Across Difference: Practice, Theory, and Research on Intergroup Dialogue. New York: Russell Sage Foundation.

Hammersley, Martyn, and Paul Atkinson. 1995. Ethnography: Principles in Practice (2nd ed.). London: Routledge.

Harper, Shaun R., and Sylvia Hurtado. 2007. "Nine Themes in Campus Racial Climates and Implications for Institutional Transformation.” New Directions for Student Services,7-24. Hartmann, Douglas, and Joseph Gerteis. 2005. “Dealing with Diversity: Mapping Multiculturalism in Sociological Terms.” Sociological Theory 23: 218-240. 
Hurtado, Sylvia. 2005. “The Next Generation of Diversity and Intergroup Relations Research.” Journal of Social Issues 61: 3: 595-610.

Joppke, Christian. 2004. "The Retreat of Multiculturalism in the Liberal State: Theory and Policy.” British Journal of Sociology 55: 237-257.

Kadison, Richard, and Theresa Foy Geronimo. 2004. College of the Overwhelmed: The Campus Mental Health Crisis and What to Do About It. San Francisco: Jossey-Bass.

Kalev, Alexandra, Frank Dobbin, and Erin Kelly. 2006. "Best Practices or Best Guesses? Assessing the Efficacy of Corporate Affirmative Action and Diversity Policies.” American Sociological Review 71: 4: 589-617.

Karabel, Jerome. 2005. The Chosen: The Hidden History of Admission and Exclusion at Harvard, Yale, and Princeton. Boston: Houghton Mifflin.

Ladson-Billings, Gloria, and William F. Tate IV. 1995. “Toward a Critical Race Theory of Education.” Teachers College Record 97: 47-68.

Lewis, Amanda E. 2003. Race in the Schoolyard: Negotiating the Color Line in Classrooms and Communities. New Brunswick, N.J.: Rutgers University Press.

Lipson, Daniel N. 2007. "Embracing Diversity: The Institutionalization of Affirmative Action as Diversity Management at UC-Berkeley, UT-Austin, and UW-Madison.” Law \& Social Inquiry 32: 4: 985-1026

Lofland, John, and Lyn H. Lofland. 1995. Analyzing Social Settings: A Guide to Qualitative Observation and Analysis. Belmont, CA: Wadsworth.

Milem, Jeffrey F., Mitchell J. Chang, and Anthony Lising Antonio. 2005. “Making Diversity Work on Campus: A Research-based Perspective.” Retrieved December 7, 2012 (http://siher.stanford.edu/AntonioMilemChang_makingdiversitywork.pdf ). 
Morning, Ann J. 2011. The Nature of Race: How Scientists Think and Teach about Human Difference. Berkeley: University of California Press.

Nathan, Rebekah. 2005. My Freshman Year: What a Professor Learned by Becoming a Student. Ithaca: Cornell University Press.

Pascoe, C. J. 2007. Dude You're a Fag: Masculinity and Sexuality in High School. Berkeley: University of California Press.

Pedersen, Jesper Strandgaard, and Frank Dobbin. 2006. “In Search of Identity and Legitimation: Bridging Organizational Culture and Neoinstitutionalism.” American Behavioral Scientist 49: 7: 897-907.

Perry, Pamela. 2002. Shades of White: White Kids and Racial Identities in High School. Durham, NC: Duke University Press.

Pike, Gary R., George D. Kuh, and Robert M. Gonyea. 2007. "Evaluating the Rationale for Affirmative Action in College Admissions: Direct and Indirect Relationships between Campus Diversity and Gains in Understanding Diverse Groups.” Journal of College Student Development 48: 2: 166-182.

Pollock, Mica. 2004. Colormute: Race Talk Dilemmas in an American School. Princeton: Princeton University Press.

Regents of the University of California v. Bakke, 438 U.S. 265 C.F.R. 1978.

Reuben, Julie A. 2001. “Merit, Mission, and Minority Students: A History of Debates over Special Admissions Programs,” In Michael C. Johanek (ed.), A Faithful Mirror: Reflections on the College Board and Education in America: pp. 195-243. New York: The College Board. Rojas, Fabio. 2007. From Black Power to Black Studies: How a Radical Social Movement became an Academic Discipline. Baltimore: Johns Hopkins University Press. 
Seaman, Barrett. 2007. Binge: College Life in an Age of Disconnection and Excess. Hoboken: Wiley.

Seidman, Irving. 2006. Interviewing as Qualitative Research: A Guide for Researchers in Education and the Social Sciences. New York: Teachers College Press.

Sidanius, Jim, Shana Levin, Colette van Laar, and David O. Sears. 2008. The Diversity Challenge: Social Identity and Intergroup Relations on the College Campus. New York: Russell Sage Foundation.

Small, Mario Luis, David J. Harding, and Michèle Lamont. 2010. "Reconsidering Culture and Poverty.” The ANNALS of the American Academy of Political and Social Science 629: 1: 627.

Smith, Sandra S., and Mignon R. Moore. 2000. "Intraracial Diversity and Relations among African-Americans: Closeness among Black Students at a Predominantly White University.” American Journal of Sociology 106: 1: 1-39.

Stevens, Mitchell L. 2007. Creating a Class: College Admissions and the Education of Elites. Cambridge, MA: Harvard University Press.

Stevens, Mitchell L., Elizabeth A. Armstrong, and Richard Arum. 2008. "Sieve, Incubator, Temple, Hub: Empirical and Theoretical Advances in the Sociology of Higher Education.” Annual Review of Sociology 34: 127-151.

Stevens, Mitchell L., and Josipa Roksa. 2011. “The Diversity Imperative in Elite Admissions,” In Lisa M. Stulberg and Sharon L. Weinberg (eds.), Diversity in American Higher Education: Toward a More Comprehensive Approach: pp. 63-73. New York: Routledge.

Stuber, Jenny M. 2011. Inside the College Gates: How Class and Culture Matter in Higher Education. Lanham, MD: Lexington Books. 
Stulberg, Lisa M., and Anthony S. Chen. 2014. "The Origins of Race-conscious Affirmative Action in Undergraduate Admissions: A Comparative Analysis of Institutional Change in Higher Education.” Sociology of Education 87: 1: 36-52.

Tajfel, Henri. 1974. “Social Identity and Intergroup Behaviour.” Social Science Information/Sur les Sciences Sociales 13: 65-93.

Thorne, Barrie. 1993. Gender Play: Girls and Boys in School. New Brunswick, NJ: Rutgers University Press.

Tyson, Karolyn. 2011. Integration Interrupted: Tracking, Black Students, and Acting White after Brown. New York: Oxford University Press.

Umbach, Paul D., George D. Kuh. 2006. "Student Experiences with Diversity at Liberal Arts Colleges: Another Claim for Distinctiveness.” Journal of Higher Education 77: 1: 169-192.

Valenzuela, Angela. 1999. Subtractive Schooling: Issues of Caring in Education of U.S.-Mexican Youth. Albany: State University of New York Press.

Voyer, Andrea. 2011. "Disciplined to Diversity: Learning the Language of Multiculturalism.” Ethnic and Racial Studies 34: 1874-1893.

Warikoo, Natasha K. 2010. "Symbolic Boundaries and School Structure in New York and London Schools.” American Journal of Education 116: 3: 423-451. 